\title{
Renascimento como metáfora para a assunção da identidade de gênero contraposta à heteronormatividade em Mulher de mim, de Mia Couto
}

Rebirth as a metaphor for the assumption of gender identity as opposed to heteronormativity in Mia Couto's Woman of me

\section{Antônio Carlos Dias Mendonça ${ }^{\mathrm{I}}$ \\ Eliane Cristina Testa ${ }^{2}$}

1 Mestrando em Literatura pela Universidade Federal do Tocantins (PPGL).

2 Professora de Literatura Portuguesa da Universidade Federal do Tocantins (UFT), onde atua também como professora do Programa de Pós-graduação em Letras (MELL). 
RESUMO: No ensaio, é analisado o conto Mulher de mim, do escritor moçambicano Mia Couto. Narrado em primeira pessoa, o texto apresenta como personagem central uma figura masculina que, desde o início, demonstra a consciência de que passava por uma transformação, que lhe levaria a se converter na "prévia matéria" (COUTO, 1998) de que havia sido formado. Esse narrador relata receber visitas noturnas de uma mulher. A princípio, ele alude a essa mulher como sendo alguém distinto de si. Pouco a pouco, essa mulher se empodera diante do narrador, de modo que é colocada em curso a metamorfose anunciada, em forma de assunção, por esse narrador, do gênero feminino. No transcorrer do texto, é evidenciado o incômodo com a presença feminina que o visita. Trata-se da negação imposta pela ideia de heteronormatividade, que o leva a recusar a condição que se intensificava, pois é subjetivado por códigos culturais. O objetivo do ensaio é discutir o modo como, literariamente, o texto examina a construção do difícil processo para a assunção de uma identidade de gênero que se contrapõe à heteronormatividade.

PALAVRAS-CHAVE: Heteronormatividade; Gênero; Renascimento; Literatura; Moçambique.

ABSTRACT: In the essay, the tale Woman of Me, by the Mozambican writer Mia Couto, is analyzed. Narrated in the first person, the text presents as a central character a male figure who, from the beginning, demonstrates the awareness that he underwent a transformation, which would lead him to become the "previous matter" (COUTO, 1998) formed. This narrator reports receiving night visits from a woman. At first, he alludes to this woman as someone other than himself. Little by little, this woman empowers herself before the narrator, so that the metamorphosis announced in the form of an assumption by this narrator of the feminine gender is put into action. In the course of the text, the discomfort with the female presence that visits him is evidenced. It is the denial imposed by the idea of heteronormativity, which leads him to refuse the condition that intensified, since it is subjectivated by cultural codes. The objective of the essay is to discuss the literary way the text examines the construction of the difficult process for the assumption of a gender identity that is opposed to heteronormativity.

KEYWORDS: Heteronormativity. Genre. Rebirth. Literature. Mozambique. 


\section{Introdução}

Os povos europeus, tendo empreendido um processo de colonização em terras dos outros continentes, de forma recorrente sobrepuseram os valores da sua cultura aos da cultura dos colonizados. Nesse processo, os dogmas e conceitos advindos da religião cristã têm um peso significativo. No caso do presente ensaio, a discussão circula em torno do conceito de gênero.

Moçambique, país localizado no sudeste do continente africano, banhado pelo oceano índico, foi colonizado por Portugal, tendo sido sua independência conquistada somente no ano de 1975 (GOVERNO DE MOÇAMBIQUE, 2017). Em função do processo de colonização, houve também um processo de aculturação, pelo qual os valores portugueses influenciaram em muitos aspectos a cultura do povo colonizado.

O peso do cristianismo sobre os valores praticados em uma sociedade não são insignificantes. Pelo contrário, uma forte característica dessa religião é a evangelização, isto é, o trabalho de conversão de pessoas sem religião ou de outras matrizes religiosas para a cristã. De forma sistemática, esse trabalho subjetiva os fiéis a seguirem uma série de dogmas. Um deles é a proibição da homossexualidade, considerada um pecado. A título de exemplo, Levítico 18:22 diz, ainda que não literalmente, que o ato sexual entre dois homens "é uma abominação" (BÍBLIA SAGRADA, 1990, p. 128).

Há, contudo, uma diferenciação entre sexo, orientação sexual e gênero. Sexo está relacionado a fatores biológicos; orientação sexual implica desejo, que é de ordem psíquica; e gênero tem relação com os códigos culturais, os quais são aprendidos no seio da sociedade.

No conto Mulher de mim, do escritor moçambicano Mia Couto, é sugerida a assunção da condição de gênero feminino por um homem. Tal assunção se dá de forma bastante conflituosa. Subjetivada pela cultura, a aceitação de sua condição ocorre por um processo doloroso, equiparável a um parto. A construção desse processo dentro do conto será discutida no ensaio considerando os símbolos e as normas como componentes da cultura que determinam a organização social, atuando no nível intermental - intersubjetivamente - que, por sua vez se desdobram nas interações sociais. 


\section{I - Fundamentação}

Segundo Sebastião Vila Nova (2009, p. 69), as “atitudes são predisposições mentais para agir de forma padronizada em situações bem específicas”. Isso significa que o agir humano não é aleatório, ou meramente fruto de alguma subjetividade individual. As pessoas em sociedade sentem e agem movidas por códigos que são aprendidos e compartilhados, constituindo, assim, conhecimentos e crenças comuns, ensinados como verdades que não podem ser violadas ou sequer contestadas.

Em sociedades cuja cultura é baseada em alguma das três grandes religiões monoteístas (cristianismo, judaísmo e islamismo), determinadas normas para orientar o sentido de ser e de agir individual funcionam como fortes componentes culturais que servem não apenas para reger condutas pessoais, como também as coletivas. Comportamentos considerados pecaminosos ou interditados no âmbito dessas religiões são reprimidos, de modo que, para não sofrer as sanções da sociedade, cada sujeito precisa reprimir em si mesmo desejos, sentimentos e interesses conflitantes com as normas, sejam elas explícitas ou tácitas.

Moçambique, apesar de ser um país africano, tem o cristianismo como religião predominante. Esse fato é explicável em função do processo de colonização realizado pelos portugueses, o que, por si só, já permite concluir que comportamentos contraditórios aos preceitos bíblicos naquele país são condenados por significativa parcela da população.

Consta no Relatório sobre a liberdade religiosa em Moçambique - 2009 (DEPARTAMENTO DE ESTADO DOS ESTADOS UNIDOS, 2017) que, do total de cristãos no país, há $24 \%$ de católicos e $22 \%$ de protestantes. Há ainda 20\% de muçulmanos, e um terço que não professa qualquer religião ou crença. Como se vê, as religiões abraâmicas incorporam mais de metade da população do país, perfazendo $66 \%$. Do total geral, 46\% são de cristãos. Cabe ressaltar que a intolerância em relação à manifestação de não heterossexualidade é semelhante ou mesmo maior entre os muçulmanos.

Assumir uma condição não heterossexual, portanto, é um fator de exclusão social. Nesse caso, assim como ocorre no Brasil, a decisão de assumir a condição de gênero feminino, por parte de alguém do sexo masculino, também em Moçambique, onde predomina o cristianismo, é considerada não somente errônea, como merecedora de sanções, sejam elas de ordem prática ou simbólica. 
Como a autorrealização é um imperativo na vida de um ser humano, assumir a identidade que se sabe autêntica é condição imprescindível para ser sujeito e, assim, realizar-se. A não assunção da identidade que constitui alguém como um ser pleno causa a desconfortável sensação de distopia, pois há a falta de liberdade, de direito e de poder.

A imposição de identidade de gênero baseada na condição biológica, contudo, é questionável.

\footnotetext{
Em muitos casos de identidades sexuais e de gênero, não há uma relação direta e simétrica entre o sexo biológico, o gênero e o desejo, como é o caso dos homossexuais, que não se adequam ao padrão da heteronormatividade. Assim, a diferença, para muitos, se torna digna de chacota, considerada pejorativa, sinônimo de exclusão social e cultural. (ARAUJO, 2011, p.27)
}

Para o autor, a sociedade ensina que cada indivíduo, atendendo a pretensos imperativos de ordem sexual, deve cumprir determinadas exigências. Por um lado, o homem deve ser viril, forte, másculo e corajoso; por outro, a mulher deve ser frágil, sensível e submissa. $\mathrm{O}$ homossexual, nesse caso, comporta um padrão situado fora das exigências sociais impostas aos indivíduos de um dos sexos, pois seu ser e seu agir denota aquele padrão que lhe é interditado. Em outras palavras, homem se identifica com o gênero feminino; mulher, com o masculino. A performance social de ambos se alinha com a do sexo oposto.

Judith Butler (2007), por sua vez, considera que a diferença sexual não é função somente de diferenças materiais. Para ela, as práticas discursivas marcam e formam essa diferença. Esse pensamento conduz ao questionamento das oposições binárias marcadas pelos elementos macho-fêmea. Ser homem ou ser mulher é uma condição genérica que, se por um lado, tem a força do componente biológico, por outro depende de uma construção que se dá por meio de discursos, que conduzem os sujeitos a diferentes práticas na sociedade.

A ultrapassagem da fronteira de gênero, portanto, é um desafio para as pessoas cujo ser demanda uma oposição a sua constituição biológica e sexual. Se para alguns esse processo ocorre de forma mais rápida e menos traumática, para outros é uma passagem causadora de angústia e de sofrimento. 


\section{2 - A metáfora do Renascimento em Mulher de mim}

A leitura de Mulher de mim possibilita uma interpretação segundo a qual uma pessoa do sexo masculino resiste em assumir a sua condição de gênero feminino. Depreende-se que ele se considera incompleto, devido a sua insatisfação com a própria sexualidade. Tal é um assunto ainda muito evitado, porque a sociedade recusa manifestações não previstas nem definidas pelas culturas passadas sobre o que significa ser homem e mulher. Isso leva a inferir que a postura assumida pelo personagem central do conto moçambicano nada mais é do que um reflexo da cultura do Ocidente, haja vista que, por muitos anos, aquele país foi colônia de Portugal.

Apesar dos intensos e frequentes debates sobre diversidade nos últimos anos, na prática, a convivência amistosa entre heterossexuais e os não heterossexuais não se consolidou. Heranças culturais são manifestadas através de preconceito e discriminação, de modo que falar de sexualidade e sexo ainda é um tabu, visto que o conservadorismo, o machismo e resquícios de tradições patriarcais e preconceituosas persistem na sociedade. Mulher de mim mostra que intelectuais do continente africano estão atentos a esse debate. O texto de Mia Couto pode ser considerado um instrumento de denúncia contra esse tipo de discriminação, proporcionando uma dialética sobre a dificuldade em assumir a homossexualidade.

No conto, o narrador se sente incomodado ao receber visitas de uma estranha. $\mathrm{Na}$ primeira visita já há a indicação de conflito interior, pois uma preocupação não permitiu que ele dormisse. Tal conflito é marcado no trecho "as horas me percorriam, insones ponteiros". Ele fala que tinha a expectativa da morte, na verdade uma substituição de um estado por outro, haja vista o uso do termo "estação". Infere-se que ele já havia se convencido que essa mudança de estado seria uma questão de tempo, pois sabia da transitoriedade da matéria. A matéria à qual se referia era algo de que ele já sabia ser formado, mas ainda não aceito.

O elemento cuja função é tentar o narrador entra em cena. Trata-se de uma mulher, a quem ele diz querer avisar que errara de endereço. Tal aviso pode ser interpretado como sendo a devoção de um sujeito subjetivado pelas normas sociais à imposição segundo a qual existe um binarismo determinado pela biologia. Ele tentava resistir àquela tentação, sem, contudo, ser capaz de impedir um abalo interior, possivelmente representado na angústia da 
mulher que, tendo se sentado na cama dele, “começou a chorar”. Um choro causado pela dor que emerge do desejo de se realizar em uma sociedade castradora.

O narrador, contudo, se sensibiliza com o sofrimento da desconhecida. Faz-lhe carícias, ao que ela reage sedutoramente, "descendo do seu decote". Novamente ele alude a uma expectativa, desta vez na forma de uma lenda antiga segundo a qual uma lua se acenderia, mas ele precisava ser forte e resistir, como os guerreiros ancestrais teriam feito. Nesse caso, continuava em marcha, em seu interior, uma luta para resistir à assunção de uma nova identidade - a identidade que de fato lhe tornaria pleno. Esse momento de impasse é denotado no trecho "eu desaparecia, intermitente, da existência". Isto é, havia uma clara oscilação entre quem ele ainda era e quem ele sabia que precisava ser. No ápice desse momento, a mulher se vai, não sem antes prometer que voltaria.

Ansioso por se suprimir, ele adormece, e diz que doeu acordar, concluindo que "a vida, ela toda, é um extenso nascimento". A dor desse acordar, comparada à dor de nascer, já é uma referência a tornar-se em um ser social cuja performance é oposta àquela do sexo a que pertence. Uma performance interditada pela cultura.

Em seu discurso, fica aludido que ele se vê como alguém que está para nascer, um "vindouro", visto como alguém a ser temido, pois pouco se sabe a seu respeito. Nesse caso, o temor pode ocorrer, na verdade, porque ele duvida de que será capaz de encarar a sociedade na pele de um ser que essa mesma sociedade repudia. Sentiu-se nostálgico das crenças infranaturais, "calcaladas convicções animais" da humanidade. Sentia-se triste e arrependido "de ter tocado aquela mulher". Depreende-se que esse trecho representa a conduta esperada de quem é educado para repudiar e negar qualquer ideia de não heterossexualidade, pois ela, segundo as escrituras cristãs, é uma abominação. Nesse momento de oscilação, contudo, o narrador questiona: “que infracção eu cometera se o desejo despontara apenas na flor dos dedos?”. A palavra "infracção", de forma explícita, demonstra o que representa, naquela cultura, desejar ser aquilo que se opõe a sua biologia. Se há infração, certamente há uma punição. O temor da punição é o impeditivo da assunção definitiva de quem deseja ser.

A mulher retorna ao quarto do narrador. Ele conclui que ela viera para retirá-lo do mundo, levá-lo "ao exílio". Em troca, ele lhe daria o próprio corpo, para que ela pudesse, efetivamente, viver. Ele reluta, tenta "encontrar a saída", pois ainda não consegue aceitar essa 
ideia. Mas ela se aproximava, "seus passos já superavam as escadas". Não havia mais tempo. Quando ela entra, ele estremece. Estremecer é aqui entendido como a adversa emoção de, mesmo sem a necessária coragem, fazer o que precisa ser feito. Não era mais possível voltar atrás. "A intrusa surgia agora com maior beleza, cada vez mais deusa, requerendo a total devoção de um crente". Como último esforço de resistência, ele lhe diz que ela só finge, e nem vê a si própria. Ela se aproxima, chama-lhe o nome docemente, passa-lhe o dedo nos lábios, perdoando aquela ofensa, aquele esforço vão e desesperado de negar o inegável, de recusar o que se mostrava tão claramente.

Ela esclarece, por fim, que não estava ali para levá-lo, mas para buscar um lugar dentro dele. Ele finalmente aquiesce: "Sem eu ser ela, eu me incompletava, feito só na arrogância das metades. Nela eu encontrava não mulher que fosse minha, mas a mulher de mim, essa que, em diante, me acenderia em cada lua".

Ela, por sua vez, faz a solicitação cuja resposta leva à transformação iminente, previsível e inevitável: “- Me deixa nascer em ti”. Então, olhos fechados, deitado, ele escuta seus próprios passos se afastando de si mesmo. Já não era ele quem estava naquele corpo, mas um novo eu, uma nova condição, um novo ser, que a partir de então precisaria enfrentar o mundo com uma nova performance.

\section{Considerações finais}

O conto Mulher de mim foi aqui examinado focalizando a demora do narrador em tomar a iniciativa de assumir a sua condição de gênero feminino, assim como na sua expectativa ou no temor de que essa decisão lhe traria sofrimento. Não se sabe se o conto metaforiza o conflito de um personagem homossexual, transexual, ou de qualquer outra classificação de gênero. Contudo, há fortes evidências de que se trata da representação de um homem que não consegue mais suportar a sua necessidade de se emancipar como um ser feminino.

Em nenhuma parte do conto o autor faz qualquer alusão às religiões monoteístas. $\mathrm{O}$ mais próximo que ele se aproxima de alguma menção ao sobrenatural ocorre quando ele fala sobre os seus ancestrais, no trecho "As lendas antigas me avisavam: virá uma que acenderá a 
lua. Se resistires, merecerás o nome da gente guerreira, o povo de quem descendes. Nem eu bem decifrava a lendável mensagem”. Contudo, a religião cristã, por ser uma realidade em Moçambique, e por sua força normatizadora do comportamento das populações onde ela predomina, é a principal referência no que concerne à obrigação de ser heterossexual. A presente leitura, nesse caso, extrapola o limite do meramente literal, e busca na intertextualidade presente nas entrelinhas o que há de cultural, o não escrito que fica subentendido.

Também não foi usada no conto uma única vez a palavra "renascimento". A raiz "nasc", como elemento lexical que concentra a significação geral de "nascer", "passar a ter vida", "passar a existir", "aparecer”, "tomar forma”, dentre tantas outras, incide dez vezes no conto. Ainda assim, a opção pelo termo "Renascimento", como metáfora para a assunção de uma identidade de gênero contraposta à heteronormatividade, foi motivada pelo fato de, materialmente, o corpo continuar sendo o mesmo. Apenas a performance do sujeito e as relações desse corpo com o mundo iriam mudar com o gesto popularizado como "sair do armário".

Em várias passagens, o conto permite interpretar que há no personagem o lado "anima" não manifestado pelo sujeito narrador. Ele se divide entre o querer e o não poder manifestar-se, baseado em contextos sociais, morais, históricos e religiosos que recalcam o seu lado feminino. Isso faz com que ele sofra e oculte o seu eu, por reprimir a sua sexualidade, que pode até ser sublimada ou negada, como forma de ser aceito socialmente, ou mesmo atender às expectativas depositadas no sujeito.

Essa modalidade de "alma" feminina não é inicialmente aceita, nem bem entendida por este sujeito que, ao percebê-la, sente-se pressionado, profundamente invadido. Sente-se preso às situações socioculturais que o impedem de integrar-se àquela alma persistente, apesar de ele se sentir incompleto. Essa situação demonstra resquícios de tradições conservadoras, machistas e preconceituosas reforçadoras do estereótipo que tem pesado sobre os não heterossexuais desde a Antiguidade.

Literariamente, o conto faz uso de dois personagens interagindo entre si. Dada a relação entre essa ficção e a realidade, pode-se interpretar a narrativa como sendo a representação de um ser que se projeta em outro, como forma de se proteger, pela vergonha de se saber aquilo que a cultura diz que se deve evitar, como forma de negar seus próprios sentimentos, criando outro que, na verdade, é aquilo que deseja ser, mas que sabe ser censurado. Deste modo, pela 
via da literatura, Mia Couto oportuniza ao leitor a possibilidade de ter contato com esse tema que, apesar de todos os avanços na área do direito e dos direitos humanos, continua sendo um tabu na sociedade. 


\section{Referências Bibliográficas}

ARAÚJO, Rubenilson Pereira de. Gênero, diversidade sexual e currículo: um estudo de caso de práticas discursivas e de (não) subjetivação no ambiente escolar. Dissertação de mestrado. Araguaína: UFT, 2011.

BERDYAEV, Nicholas. The Destiny of Man. Harper Tochbooks, Nova Iorque, 1960, pp. 61-62.

BÍBLIA SAGRADA. Edição Pastoral. São Paulo: Paulus, 1990.

BUTLER, Judith. Corpos que pesam: sobre os limites discursivos do "sexo". In: CABAÇO, José Luis. Moçambique: identidade, colonialismo e libertação. São Paulo: Editora UNESP, 2009 360p.

COUTO, Mia. Cada homem é uma raça-estórias, Rio de janeiro: Nova Fronteira, 1998.

DEPARTAMENTO DE ESTADO DOS ESTADOS UNIDOS. Relatório sobre a liberdade religiosa em Moçambique - 2009. Disponível em: <https://www.state.gov/documents/organization/132927.pdf>. Acesso em: 19 dez. 2017.

GOVERNO DE MOÇAMBIQUE. A Luta pela Independência. Disponível em: <http://www. portaldogoverno.gov.mz/por/Mocambique/Historia-de-Mocambique/A-Luta-pela-Independencia>. Acesso em 19 dez. 2017.

JOHNSON, Robert A. I92 I-SHE: a chave do entendimento da psicologia feminina: uma interpretação baseada no mito de Eros e Psiquê,usando conceitos psicológicos jungianos. Tradução de Maria Helena de Oliveira Tricca. São Paulo: Mercuryo, 1987.

LOURO, Guacira Lopes (Org.). O corpo educado: pedagogias da sexualidade. Belo Horizonte: Autêntica, 2007. 
REVISTA SER HOMEM $\mathrm{n}^{\circ} 1$ : Entendendo as masculinidades by Bagabaga Studios.

SANFORD, John A .Os parceiros invisíveis: o masculino e o feminino dentro de cada um de nós. São Paulo: Paulus, 1986 (Coleção amor e psique).

VILA NOVA, Sebastião. Introdução à Sociologia. São Paulo: Atlas, 2009. 